\title{
Evaluation of the MTHFR C677T Polymorphism as a Risk Factor for Colorectal Cancer in Asian Populations
}

\author{
Vandana Rai
}

\begin{abstract}
Background: Genetic and environmental factors play important roles in pathogenesis of digestive tract cancers like those in the esophagus, stomach and colorectum. Folate deficiency and methylenetetrahydrofolate reductase (MTHFR) as an important enzyme of folate and methionine metabolism are considered crucial for DNA synthesis and methylation. MTHFR variants may cause genomic hypomethylation, which may lead to the development of cancer, and MTHFR gene polymorphisms (especially C677T and A1298C) are known to influence predispositions for cancer development. Several case control association studies of MTHFR C677T polymorphisms and colorectal cancer (CRC) have been reported in different populations with contrasting results, possibly reflecting inadequate statistical power. $\underline{\text { Aim: }}$ : The present meta-analysis was conducted to investigate the association between the C677T polymorphism and the risk of colorectal cancer. Materials and Methods: A literature search of the PubMed, Google Scholar, Springer link and Elsevier databases was carried out for potential relevant articles. Pooled odds ratio (OR) with corresponding $95 \%$ confidence interval (95 \% CI) was calculated to assess the association of MTHFR C677T with the susceptibility to CRC. Cochran's Q statistic and the inconsistency index $\left(\mathrm{I}^{2}\right)$ were used to check study heterogeneity. Egger's test and funnel plots were applied to assess publication bias. All statistical analyses were conducted by with MetaAnalyst and MIX version 1.7. Results: Thirty four case-control studies involving a total of 9,143 cases and 11,357 controls were retrieved according to the inclusion criteria. Overall, no significant association was found between the MTHFR C677T polymorphism and colorectal cancer in Asian populations (for $\mathrm{T}$ vs. $\mathrm{C}$ : $\mathrm{OR}=1.03 ; 95 \% \mathrm{CI}=0.92-1.5$; $\mathrm{p}=0.64$; for $\mathrm{TT}$ vs $\mathrm{CC}$ : $\mathrm{OR}=0.88 ; 95 \% \mathrm{CI}=0.74-1.04 ; \mathrm{p}=0.04$; for $\mathrm{CT} v \mathrm{vs} . \mathrm{CC}: \mathrm{OR}=1.02 ; 95 \% \mathrm{CI}=0.93-1.12$; $\mathrm{p}=0.59$; for $\mathrm{TT}+\mathrm{CT} v \mathrm{v}$. $\mathrm{CC}: \mathrm{OR}=1.07 ; 95 \% \mathrm{CI}=0.94-1.22 ; \mathrm{p}=0.87)$. Conclusions: Evidence from the current meta-analysis indicated that the C677T polymorphism is not associated with CRC risk in Asian populations. Further investigations are needed to offer better insight into any role of this polymorphism in colorectal carcinogenesis.
\end{abstract}

Keywords: Colorectal cancer - MTHFR - C677T - meta-analysis - homocysteine - folate

Asian Pac J Cancer Prev, 16 (18), 8093-8100

\section{Introduction}

Colorectal cancer (CRC) is the second most common cancer worldwide and $60 \%$ cases occur in developed regions. The incidence varies considerably among different ethnicities (Parkin et al., 1999; Ferlay et al., 2008; Center et al., 2009; Jemal et al., 2009; Yousef et al., 2014). Although incidence rates are lower in Asian than Caucasian populations (Jang et al., 2013). Fifty percentage of the people diagnosed with colorectal cancer will die of the disease (Boyle and Ferlay, 2005; Li et al., 2011). CRC is a multifactorial disease with involvement of both genetic and environmental factors. Epidemiological studies have indicated that diets plays an important role in colorectal malignancy, high intake of alcohol and red meat and low intake of folate i.e green vegetables, fruits and dietary fibres are increased the risk of CRC (Russo et al., 1998; Bedine, 1999; Boutron-
Ruault et al., 2001; Giovannucci, 2001; Giovannucci et al., 1995). High folate intake has protective effect against CRC (Giovannucci et al., 1995; Wang et al., 2006). Folate metabolism is regulated by several enzymes and out of which methylenetetrahydrofolate reductase (MTHFR) is the critical enzyme and genetic polymorphism of MTHFR enzyme is considered as a potential marker that may influence the risk of CRC.

MTHFR enzyme is involved in DNA synthesis, repair and methylation (Sameer et al., 2011). It is responsible for determining whether reduced folates are directed towards DNA methylation pathways or DNA synthesis (Ryan and Weir, 2001). The MTHFR locus has been mapped to chromosome 1p36.3 in humans (Goyette et al., 1994). The most well-studied polymorphism in MTHFR gene is the replacement of the nucleotide thymine by cytosine at position 677 (Ala222Val) (Frosst et al., 1995). This variant, which is relatively common in many populations 


\section{Vandana Rai}

worldwide, produces a form of methylenetetrahydrofolate reductase that reduces activity at higher temperatures, leading to lower levels of circulating folate (5-methylTHF), an accumulation of 5, 10-methylene-THF, and increased plasma homocystein levels (Ma et al., 1997; Yan et al., 2012). The frequency of $\mathrm{T}$ allele varies in different ethnic population. According to HapMap database, the highest frequency i.e 0.48 is reported from Chinese Han population and $\mathrm{T}$ allele frequency in Europeans, Africans, Japanese and Indians is reported as $0.31,0.08$ to $0.12,0.38$ and 0.16 respectively (http:// hapmap.ncbi.nlm.nih.gov). Previous studies have suggested that $\mathrm{T}$ allele frequency can be higher in regions where food and vitamins are sufficient, as higher homocysteine and low-folate levels are compensated (Kennedy et al., 2012). MTHFR C677T had been suggested as a possible risk factor for congenital anomalies, heart disease, stroke, diabetes, psychiatric disorders and certain types of cancer (Fu et al., 2013; Rai et al., 2014; Rai 2014a, b).

DNA strand breaks, impaired DNA methylation and repair have been associated with folate deficiency and CRC (Duthie, 1999; Ames, 2001; Fenech, 2001; Kim, 2003). Several studies from around the globe have indicated that the common polymorphisms in the MTHFR gene might play a critical role in increasing susceptibility to CRC (Park et al., 1999; Yin et al., 2004). However, some other studies suggested that the MTHFR C677T polymorphisms were not associated with susceptibility to CRC (Chen et al., 1996; Ma et al., 1997; Slattery et al., 1999; Sachse et al., 2002; Shannon et al., 2002). In view of the conflicting results from previous studies, present metaanalysis of all available data was performed to evaluate the association between MTHFR C677T polymorphisms and susceptibility to CRC.

\section{Materials and Methods}

\section{Literature search strategy and inclusion criteria:}

Meta-analysis was performed according to MOOSE guidelines (Stroup et al., 2000). A literature search of the PubMed, Google Scholar, Elsevier and Springer Link databases was conducted to identify articles published up to July, 2014, with following keywords: using the following terms: ("genetic polymorphism" or "polymorphism" or "SNP" or "single nucleotide polymorphism" or "gene mutation" or "genetic variants") and ("Colorectal cancer" or "colon cancer" or "rectal cancer") and ("MTHFR" or "methylenetetrahydrofolate reductase" or "C677T"). Bibliographies of review articles were manually searched to find additional eligible studies. If more than one study by the same author using the same case series was published, either the studies with the largest sample size or the most recently published study was included. Included studies had to fit the following criteria:(1) sufficient data regarding allele frequency; (2) an association analysis between the MTHFR C677T polymorphism and CRC risk; and (3) independent casecontrol studies.

\section{Data extraction}

The following information was extracted from the each identified studies: the first author family name, year of publication, sample size, country name, genotyping method, the numbers of patients and controls, MTHFR C677T genotypes information and frequencies of alleles in all study. For data not provided in the main text, the relevant information was obtained by contacting corresponding authors.

\section{Statistical analysis}

The strength of the association between MTHFR C677T polymorphisms and colorectal risk was measured by using crude odds ratio (OR) with $95 \%$ confidence interval (CI). The pooled ORs were estimated in following genetic models: allele contrast ( $\mathrm{T} v s . \mathrm{C})$, codominant model (CT vs. CC), homozygote model (TT vs. CC), dominant model (TT+CT vs. CC), and recessive model (TT vs. CT+CC). Heterogeneity among studies was examined with the $\chi^{2}$ test-based $\mathrm{Q}$ statistics and $\mathrm{P}<0.05$ was considered significant. Heterogeneity was quantified with the $\mathrm{I}^{2}$ metric, which is independent of the number of studies in the meta-analysis (Zintzaras and Lau, 2008). $\mathrm{I}^{2}$ takes values between $0 \%$ and $100 \%$, with higher values indicating a greater degree of heterogeneity. Fixedeffects summary ORs were calculated using the MantelHaenszel method (Mantel and Haenszel, 1959), and the DerSimonian and Laird method was used to calculate random-effects summary ORs (DerSimonian and Laird, 1986).

Egger's test and an inverted funnel plot was used to assess publication bias (Begg and Mazumdar, 1994; Egger et al., 1997). HWE was checked in the control group of the eligible studies by the chi-square test ( $\mathrm{p} \leq 0.05)$. Sensitivity analysis was performed including studies that deviated from HWE and with small sample size. Methodological quality was assessed according to the Newcastle-Ottawa Scale (NOS) criteria (Stang, 2010). The NOS criteria includes three aspects: (1) subject selection: 0, 4 points; (2) comparability of subject: 0, 2 points; (3) clinical outcome: 0,3 points. NOS scores range from 0 to 9 with a score $>7$ indicating good quality (Yan et al., 2013). All statistical analysis was undertaken using the program MetaAnalyst and MIX version 1.7 (Bax et al., 2006). All $P$ values were two-sided.

\section{Results}

\section{Eligible studies:}

A flow chart summarizing the process of study selection is shown in Figure 1. Initially, the highly sensitive search strategy of Pubmed, Google Scholar, Elsevier and Springer Link databases, 383 articles were retrieved. After screening the titles and abstracts of all retrieved articles, 189 articles were excluded. Then full texts were reviewed and 85 articles were further excluded and remaining 109 articles were further reviewed. Another 20 studies were excluded because 16 studies reported only cases and 4 studies were meta-analysis. 55 articles from remaining 89 articles were again excluded because studied population was not Asian. Based on the inclusion and exclusion criteria, finally, thirty four studies met the inclusion criteria and were included in the present met- 
Evaluation of the MTHFR C677T Polymorphism as a Risk Factor for Colorectal Cancer in Asian Populations

analysis (Park et al., 1999; Le Marchand et al., 2002; Matsuo et al., 2002; Huang et al., 2003; Kim et al., 2004; Yin et al., 2004; Jiang et al., 2005; Matsuo et al., 2005; Miao et al., 2005; Otani et al., 2005; Wang et al., 2006; Chang et al., 2007; Jin et al., 2007; Zeybek et al., 2007; Cao et al., 2008; Haghighi et al., 2008; Mokarram et al., 2008; Zhang et al., 2008; El-Awady et al., 2009; Chandy et al., 2010; Cui et al., 2010; Naghibalhossaini et al., 2010; Promthet et al., 2010; Yang et al., 2010; Zhu et al., 2010; Kang et al., 2011; Kim et al., 2011; Li et al., 2011; Prasad and Wilkhoo, 2011; Sameer et al., 2011; Zhu et al., 2011; Yin et al., 2011; Kim et al., 2012; Ozen et al., 2014).

\section{Characteristic of included studies}

The main characteristics of the included studies were shown in Table 1. A total of 20,500 subjects were involved in this meta-analysis, including 9, 143 CRC patients and 11, 357 healthy controls. The publication years of

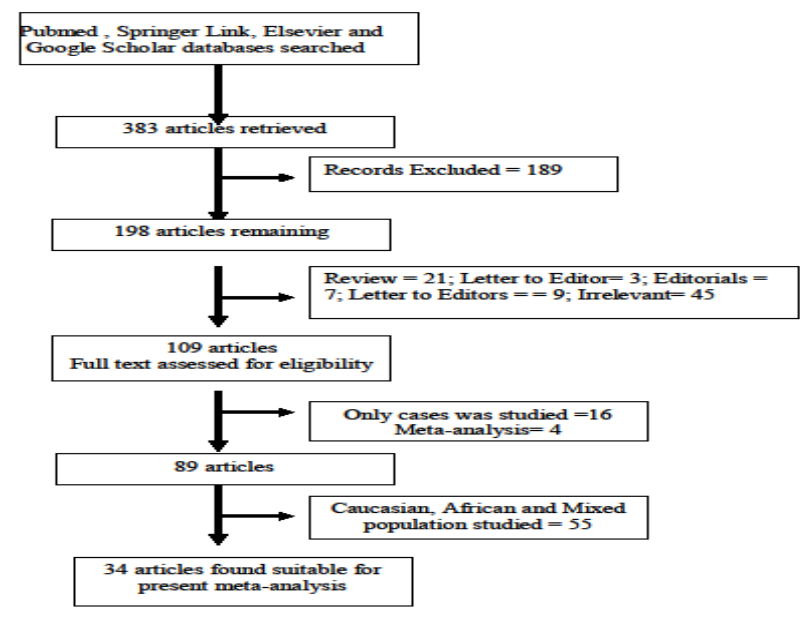

Figure 1. Flow Chart Shows Study Selection Procedure. Thirty four case control studies were included in this metaanalysis

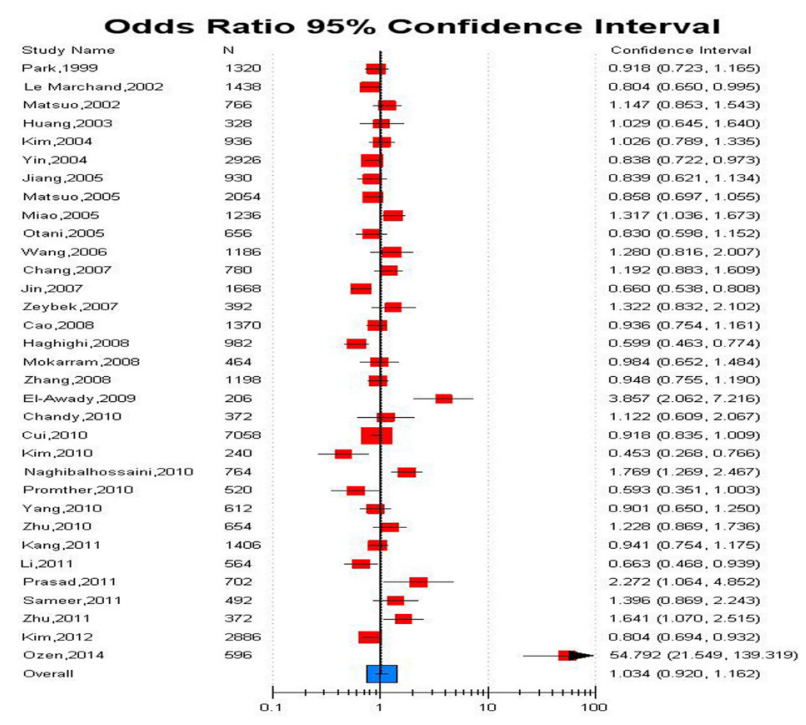

Figure 2. Forest Plots for the Association between MTHFR C677T Polymorphism and Colorectal Cancer for Allele Contrast Model (T vs C) with Fixed Effect Model in Asian Population the involved studies ranged from 1999 to 2014. Sample size ranged from 35 to 1,829 in cases and 53 to 1700 in controls. Most reports presented demographic information regarding cases and controls. Genotyping was performed consistently across studies with polymerase chain reaction (PCR). In controls genotype percentage of CC, CT and TT were $40.45 \%, 43.30 \%$ and $16.24 \%$ respectively. In cases genotype percentage of CC, CT and TT were $40.59 \%$, $45.66 \%$ and $13.75 \%$ respectively. Except four studies (Haghighi et al., 2008; Kang et al., 2011; Sameer et al., 2011; Kim et al., 2012), distribution of genotypes in the controls of thirty studies was consistent with HardyWeinberg equilibrium. OR of fourteen studies (Matsuo et al., 2002; Kim et al., 2004; Miao et al., 2005; Wanget al., 2006; Chang et al., 2007; Cao et al., 2008; El-Awady et al., 2009; Chandy et al., 2010; Naghibalhossaini et al., 2010; Zhu et al., 2010; Prasad and Wilkhoo, 2011; Sameer et al., 2011; Zhu et al., 2011; Ozen et al., 2014) was above one and other twenty studies did not show any association between MTHFR C677T polymorphism and CRC. All these thirty four studies were performed in

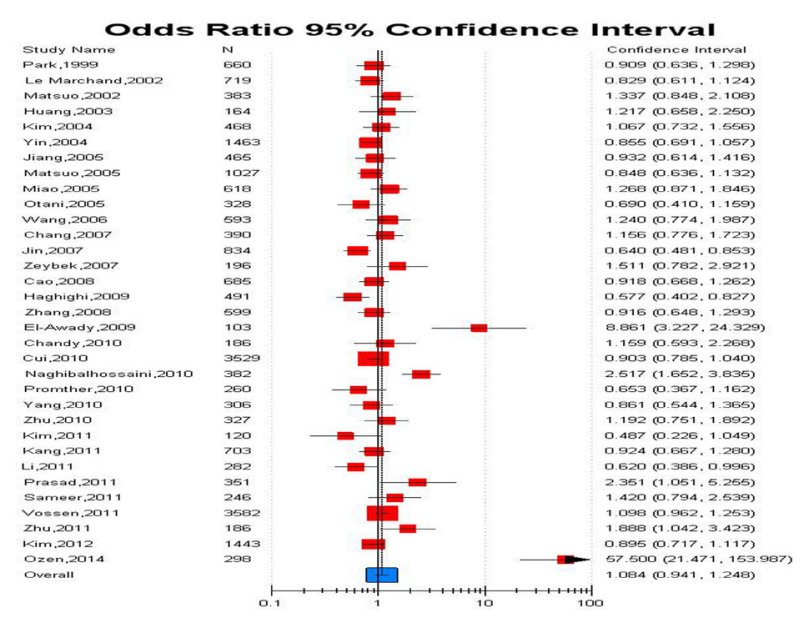

Figure 3. Forest Plots for the Association between MTHFR C677T Polymorphism and Colorectal Cancer for Dominant Model (TT+CT vs CC) with Fixed Effect Model in Asian Population

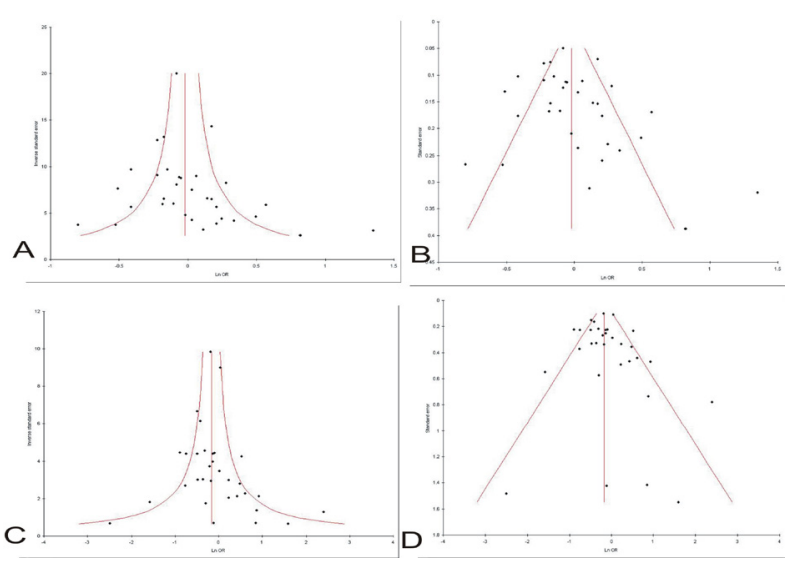

Figure 4. Funnel Plots. A. precision versus OR for additive model (T vs. C), B. standard error versus OR for additive model (T vs. C),C. precision versus OR for TT+CT vs CC, D. standard error versus $\mathrm{OR}$ for $\mathrm{TT}+\mathrm{CT}$ vs $\mathrm{CC}$. 


\section{Vandana Rai}

different countries -China (Huang et al., 2003; Jiang et al., 2005; Miao et al., 2005; Chang et al., 2007; Jin et al., 2007; Cao et al., 2008; Zhang et al., 2008; Yang et al., 2010; Zhu et al., 2010; Li et al., 2011; Zhu et al., 2011), Egypt (El-Awady et al., 2009), India (Wang et al., 2006; Chandy et al., 2010; Prasad and Wilkhoo, 2011; Sameer et al., 2011), Iran (Haghighi et al., 2008; Mokarram et al., 2008; Naghibalhossaini et al., 2010), Korea (Park et a., 1999; Kim et al., 2004; Cui et al., 2010; Kim et al., 2011; Kang et al., 2011; Kim et al., 2012), Japan (Le Marchand et al., 2002; Matsuo et al., 2002; 2005; Yin et al., 2004; Otani et al., 2005), Thailand (Promther et al., 2010), Turkey (Zeybek et al., 2007; Ozen et al., 2014).

\section{Meta-analysis}

The association between MTHFR C677T and CRC risk in allele contrast, dominant, homozygote, co-dominant and recessive models was shown in Table 2. Meta-analysis with allele contrast ( $\mathrm{T}$ vs $\mathrm{C}$ ) did not show association with both fixed effect $\left(\mathrm{OR}_{\mathrm{TvSC}}=0.94 ; 95 \% \mathrm{CI}=0.90-0.98\right.$; $\left.\mathrm{p}=0.001 ; \mathrm{I}^{2}=74.54 \% ; \mathrm{P}_{\text {heterogeneity }}<0.0001 ; \mathrm{P}_{\mathrm{Pb}}=0.12\right)$ and random effect model $\left(\mathrm{OR}_{\mathrm{TvsC}}=1.03 ; 95 \% \mathrm{CI}=0.92-1.5\right.$; $\mathrm{p}=0.64$ ) (Table 2, Figure 2).

Increased risk of colorectal cancer was not observed among mutant homozygote variants (TTvsCC; homozygote model $)$ using both fixed $\left(\mathrm{OR}_{\mathrm{TTvSCC}}=0.81\right.$; 95\% CI $=0.75-0.88 ; \mathrm{p}<0.0001 ; \mathrm{I}^{2}=61.88 .84 \% ; \mathrm{P}_{\text {heterogeneity }}$ $\left.<0.0001 ; \mathrm{P}_{\mathrm{Pb}}=0.27\right)$ and random $\left(\mathrm{OR}_{\mathrm{TTvsCC}}=0.88 ; 95 \% \mathrm{CI}=\right.$

Table 1. Characteristics of Thirty four Studies Included in the Present Meta-analysis

\begin{tabular}{|c|c|c|c|c|}
\hline Study & Country & Case No. & Control No. & $\mathrm{P}$ value of HWE \\
\hline Park et al., 1999 & Korea & 200 & 460 & 0.05 \\
\hline Le Marchand et al., 2002 & Japan & 322 & 397 & 0.22 \\
\hline Matsuo et al., 2002 & Japan & 142 & 241 & 0.3 \\
\hline Yin et al., 2002 & Japan & 685 & 778 & 0.52 \\
\hline Huang et al., 2003 & China & 82 & 82 & 0.58 \\
\hline Kim et al., 2004 & Korea & 243 & 225 & 0.77 \\
\hline Yin et al., 2004 & Japan & 685 & 778 & 0.52 \\
\hline Jiang et al., 2005 & China & 125 & 340 & 0.33 \\
\hline Matsuo et al., 2005 & Japan & 256 & 771 & 0.09 \\
\hline Miao et al., 2005 & China & 198 & 420 & 0.52 \\
\hline Otani et al., 2005 & Japan & 106 & 222 & 0.67 \\
\hline Wang et al., 2006 & Indian & 302 & 291 & 0.26 \\
\hline Chang et al., 2007 & China & 195 & 195 & 0.46 \\
\hline Jin et al., 2007 & China & 334 & 500 & 0.34 \\
\hline Zeybek et al., 2007 & Turkey & 52 & 144 & 0.8 \\
\hline Cao et al., 2008 & China & 315 & 370 & 0.82 \\
\hline Haghighi et al., 2008 & Iran & 234 & 257 & 0 \\
\hline Mokarram et al., 2008 & Iran & 151 & 81 & 0.31 \\
\hline Zhang et al., 2008 & China & 300 & 299 & 0.26 \\
\hline El-Awady et al., 2009 & Egypt & 35 & 68 & 0.41 \\
\hline Chandy et al., 2010 & India & 100 & 86 & 0.78 \\
\hline Cui et al., 2010 & Korea & 1829 & 1700 & 0.13 \\
\hline Kim et al., 2011 & Korea & 67 & 53 & 0.13 \\
\hline Naghibalhossaini et al., 2010 & Iran & 151 & 231 & 0.16 \\
\hline Promther et al., 2010 & Thailand & 130 & 130 & 0.24 \\
\hline Yang et al., 2010 & China & 141 & 165 & 0.51 \\
\hline Zhu et al., 2010 & China & 216 & 111 & 0.23 \\
\hline Kang et al., 2011 & Korea & 255 & 448 & 0.04 \\
\hline Li et al., 2011 & China & 137 & 145 & 0.33 \\
\hline Prasad and Wilkhoo,2011 & India & 110 & 241 & 0.07 \\
\hline Sameer et al., 2011 & India & 86 & 160 & 0 \\
\hline Zhu et al., 2011 & China & 86 & 100 & 0.74 \\
\hline Kim et al., 2012 & Korea & 787 & 656 & 0.003 \\
\hline Ozen et al., 2014 & Turkey & 86 & 212 & 0.86 \\
\hline
\end{tabular}


Evaluation of the MTHFR C677T Polymorphism as a Risk Factor for Colorectal Cancer in Asian Populations

Table 2. Summary estimates for the odds ratio (OR) of MTHFR C677T in various allele/genotype contrasts, $p$ value of heterogeneity test $\left(Q\right.$ test), $I^{2}$ metric and p-value of Egger test

\begin{tabular}{|l|c|c|c|c|c|}
\hline \multicolumn{1}{|c|}{ OR } & $\begin{array}{c}\text { Fixed effect } \\
(\mathrm{OR}(95 \% \mathrm{CI}), \mathrm{p})\end{array}$ & $\begin{array}{c}\text { Random effect } \\
(\mathrm{OR}(95 \% \mathrm{CI}), \mathrm{p})\end{array}$ & $\begin{array}{c}\text { Heterogeneity } \\
\text { p-value (Q test) }\end{array}$ & $\mathrm{I}^{2}(\%)$ & $\begin{array}{c}\text { Publication Bias } \\
\text { (p of Egger's test) }\end{array}$ \\
\hline $\begin{array}{l}\text { Allele Contrast } \\
(\mathrm{T} \text { vs C) }\end{array}$ & $0.94(0.90-0.98), 0.001$ & $1.03(0.92-1.5), 0.64$ & $<0.0001$ & 74.54 & 0.12 \\
\hline $\begin{array}{l}\text { Co-dominant } \\
(\mathrm{CT} \text { vs CC) }\end{array}$ & $1.01(0.95-1.1), 0.79$ & $1.02(0.93-1.12), 0.59$ & 0.0003 & 52.04 & 0.17 \\
\hline $\begin{array}{l}\text { Homozygoote } \\
(\mathrm{TT} \text { vs CC) }\end{array}$ & $0.81(0.75-0.88),<0.0001$ & $0.88(0.74-1.04), 0.04$ & $<0.0001$ & 61.88 & 0.27 \\
\hline $\begin{array}{l}\text { Dominant } \\
(\mathrm{TT}+\mathrm{CT} \text { vs CC) }\end{array}$ & $0.96(0.90-1.01), 0.16$ & $1.07(0.94-1.22), 0.87$ & $<0.001$ & 65.6 & 0.17 \\
\hline $\begin{array}{l}\text { Recessive } \\
(\mathrm{TT} \text { vs CT+CC) }\end{array}$ & $0.82(0.76-0.88),<0.0001$ & $0.84(0.74-0.96), 0.01$ & 0.0002 & 53.1 & 0.39 \\
\hline
\end{tabular}

0.74-1.04; $\mathrm{p}=0.04)$ effect models and high statistical heterogeneity was also found. Association of mutant heterozygous genotype (CT vs.CC; co-dominant model) was not observed significant with both fixed $\left(\mathrm{OR}_{\mathrm{CTvsCC}}=\right.$ $1.01 ; 95 \% \mathrm{CI}=0.95-1.1 ; \mathrm{p}=0.79 ; \mathrm{I}^{2}=52.04 \% ; \mathrm{P}_{\text {heterogeneity }}=$ $0.0003 ; \mathrm{PPb}=0.17)$ and random $\left(\mathrm{OR}_{\mathrm{CTvSCC}}=1.02 ; 95 \% \mathrm{CI}=\right.$ $0.93-1.12 ; \mathrm{p}=0.59)$ effect models. Similarly combined mutant genotypes (TT+CT vs. CC; dominant model) did not show positive association with colorectal cancer using both fixed $\left(\mathrm{OR}_{\mathrm{TT}+\mathrm{CT} \text { vsCC }}=0.96 ; 95 \% \mathrm{CI}=0.90-1.01\right.$; $\left.\mathrm{p}=0.16 ; \mathrm{I}^{2}=65.6 \% ; \mathrm{P}_{\text {heterogeneity }}<0.0001 ; \mathrm{P}_{\mathrm{Pb}}=0.17\right)$ and random $\left(\mathrm{OR}_{\mathrm{TT}+\mathrm{CT} \text { vsCC }}=1.07 ; 95 \% \mathrm{CI}=0.94-1.22 ; \mathrm{p}=0.87\right)$ effect models (Table 2; Figure 3).

\section{Sensitivity analysis}

Sensitivity analyses by sequential omission of individual studies or studies with low quality (studies departed from HWE or with small sample size) did not alter the overall pooled ORs. The genotype distribution of the control population in four studies (Haghighi et al., 2008; Kang et al., 2011; Sameer et al., 2011; Kim et al., 2012) was not in HWE. Overall, the results from sensitivity analysis after exclusion of these four studies were similar to those from nonsensitivity analysis, and MTHFR C677T allele or TT genotype was not associated with CRC susceptibility $\left(\mathrm{OR}_{\mathrm{TvsC}}=0.96 ; 95 \% \mathrm{CI}=0.91-1.00\right.$; $\left.\mathrm{p}=0.008 ; \mathrm{I}^{2}=83.6 \% ; \mathrm{P}_{\text {heterogeneity }}<0.0001\right)$.

Sensitivity analysis for the relationship between the MTHFR C677T gene polymorphism and CRC risk according to sample size of case $(<100)$ was also performed. The results of exclusion of seven studies with samples size less than 100 (Huang et al., 2003, n=82; Zeybek et al., 2007, n=52; El-Awady et al., 2009, $n=35$; kim et al., 2010, n=67; Sameer et al., 2011, n=86; Zhu et al., 2011, n=86; Ozen et al., 2014, n=86) were similar as the non-sensitivity analysis, and $\mathrm{T}$ allele was not associated with CRC susceptibility $\left(\mathrm{OR}_{\mathrm{TvsC}}=0.93 ; 95 \% \mathrm{CI}=0.89-0.97\right.$; $\left.\mathrm{p}=0.001 ; \mathrm{I}^{2}=71.04 \% ; \mathrm{P}_{\text {heterogeneity }}<0.0001\right)$.

\section{Bias diagnosis}

Begg funnel plot and Egger test were performed to assess publication bias. Egger test was used to provide statistical evidence for funnel plot symmetry. The Funnel plots' shape of all contrasts did not reveal obvious evidence of asymmetry (Figure 4A-D), and all the Pvalues of Egger's test were more than 0.05, providing statistical evidence for the funnel plots' symmetry (Table 2).

\section{Discussion}

In present study, the possible association between the C677T polymorphisms of MTHFR gene and CRC was investigated with a meta-analysis. The results showed that MTHFR C677T polymorphism is not associated with CRC. Colorectal cancer is an important clinical problem which has been well-studied but its mechanism is still relatively unclear. DNA methylation is an important epigenetic process for transcriptional control of human genome including those genes involved in cancer initiation and progression. Clinical studies have suggested that biological explanation to the protective effect of some nutrients could be linked with the DNA methylation (Galvan-Portillo et al., 2009). The metabolism of folate is significant for the maintenance of genome integrity due to its role in DNA synthesis, repair, and methylation (Fowler, 2005). Defects in folate metabolism can arise from a poor dietary intake of folates and other nutrients or may be determined genetically as a result of the combined influence of many low-penetration mutations or single nucleotide polymorphisms (SNPs). These genetic polymorphisms could modify the activity, stability, or level of the corresponding enzymes and thereby impair folate absorption or disturb the balance between folate derivatives (Weiwei et al., 2014).

Several large-scale meta-analyses combining data from multiple studies have been published investigating the association between MTHFR C677T polymorphism and various cancers such as gastric, lung cancer, breast cancer, cervical cancer, and liver cancer (Zintzaras, 2006; Bai et al., 2009; Jin et al., 2009; Ding et al., 2012; Mei et al., 2012; Niu et al., 2012; Tu et al., 2012; Zhuo et al., 2012; Wen et al., 2013; You et al., 2013; Rai, 2014, a, b). Some reports demonstrated association between MTHFR C677T polymorphism and cancer (You et al., 2013; Rai, 2014a), whereas others reported contradictory results i.e no association (Ding et al., 2012; Niu et al., 2012). These inconsistent and confusing conclusions can be attributed to several factors like (i) different selection criteria and 


\section{Vandana Rai}

selection bias might account for the diversity of the results, (ii) folate metabolic pathway is complex pathway and MTHFR is only one of many enzymes involved in the pathway, (iii) the studies with small sample size were included in the meta-analyses and these studies have lower statistical power than those with large sample size and ( $i v)$ finally different mechanisms of carcinogenesis of different cancers might due to gene-variant associations vary in different kinds of diseases (Qin et al., 2014). This contradiction suggests that the effect of the C677T polymorphism of MTHFR on the susceptibility to cancer may vary in different cancer type in different populations.

Heterogeneity is a critical issue in any meta-analysis, and an important aim of a meta-analysis is to determine the source and causes of heterogeneity. Evidence of betweenstudy heterogeneities was observed in allelic contrast, co-dominant, homozygote, dominant and recessive models, therefore the random effect models were adopted and sensitivity analyses were done (Zhang et al., 2014). However, author failed to find the source of heterogeneity by conducting sensitivity analyses.

The present meta-analysis on CRC and MTHFR C677T association is more reliable than previous metaanalysis studies because it included the latest published articles and a larger sample size. However it has some limitations also. First, the results were based on unadjusted ORs, while a more precise evaluation should be adjusted by potentially confounding factors, including age, gender, body mass index, smoking status, drink abuse, and environmental factors. Second, the controls were not uniformly defined. Some studies used population-based controls, while others used hospital based controls. Third, single gene of folate pathway was considered in present meta-analysis. Finally, the effect of gene-gene and geneenvironment interactions was not considered.

In summary, present meta-analysis indicated that C677T polymorphism in the MTHFR gene may not be associated with CRC susceptibility in Asians. Welldesigned prospective studies with large sample size should be conducted to validate findings of the present meta-analysis..

\section{References}

Ames BN (2001). DNA damage from micronutrient deficiencies is likely to be a major cause of cancer. Mutat Res, 475, 7-20.

Bax L, Yu LM, Ikeda N, Tsuruta H. Moons KG (2006). Development and validation of MIX: comprehensive free software for meta-analysis of causal research data. $B M C$ Med Res Methodol, 6, 50.

Bedine MS (1999). Colorectal carcinoma: etiology, diagnosis, and screening. Compr Ther, 25, 163-8.

Begg CB, Mazumdar M (1994). Operating characteristics of a rank correlation test for publication bias. Biometrics, $\mathbf{5 0}$, 1088-101.

Bai JL, Zheng MH, Xia X, et al (2009). MTHFR C677T polymorphism contributes to prostate cancer risk among Caucasians: A meta-analysis of 3511 cases and 2762 controls. Eur J Cancer, 45, 1443-9.

Boutron-Ruault MC, Senesse P, Meance S, Belghiti C, Faivre J (2001). Energy intake, body mass index, physical activity, and the colorectal adenomacarcinoma sequence. Nutr
Cancer, 39, 50-7.

Boyle P, Ferlay J (2005). Cancer incidence and mortality in Europe, 2004. Ann Oncol, 16, 481-8.

Cao HX, Gao CM, Takezaki T, et al (2008). Genetic polymorphisms of methylenetetrahydrofolate reductase and susceptibility to colorectal cancer. Asian Pac J Cancer Prev, 9, 203-8.

Center MM, Jemal A, Ward E (2009). International trends in colorectal cancer incidence rates. Cancer Epidemiol Biomarkers Prev, 18, 1688-94.

Chandy S, Sadananda Adiga MN, Ramachandra N, et al (2010). Association of methylenetetrahydrofolate reductase gene polymorphisms and colorectal cancer in India. Indian J Med Res, 131, 659-64.

Chang SC, Lin PC, Lin JK, et al (2007). Role of MTHFR polymorphisms and folate levels in different phenotypes of sporadic colorectal cancers. Int J Colorectal Dis, 22, 483-9.

Chen J, Giovannucci E, Kelsey K, et al (1996). A methylenetetrahydro folate reductase polymorphism and the risk of colorectal cancer. Cancer Res, 56, 48624864.

Cui LH, Shin MH, Kweon SS, et al (2010). Methylenetetrahydrofolate reductase $\mathrm{C} 677 \mathrm{~T}$ polymorphism in patients with gastric and colorectal cancer in a Korean population. BMC Cancer, 10, 236.

DerSimonian R, Laird N (1986). Meta-analysis in clinical trials. Control Clin Trials, 7, 177-88.

Ding XP, Feng L, Ma L (2012). MTHFR C677T polymorphism and ovarian cancer risk: a meta-analysis. Asian Pac J Cancer Prev, 13, 3937-42.

Duthie SJ (1999). Folic acid deficiency and cancer: mechanisms of DNA instability. Br Med Bull, 55, 578-92.

Egger M, Davey Smith G, Schneider M, Minder C (1997). Bias in meta-analysis detected by a simple, graphical test. $B M J$, 315, 629-34.

El Awady MK, Karim AM, Hanna LS, et al (2009). Methylenetetrahydrofolate reductase gene polymorphisms and the risk of colorectal carcinoma in a sample of Egyptian individuals. Cancer Biomark, 5, 233240.

Fenech M (2001). The role of folic acid and Vitamin B12 in genomic stability of human cells. Mutat Res, 475, 57-67.

Ferlay J, Shin HR, Bray F, et al (2008). Cancer Incidence and Mortality Worldwide: GLOBOCAN 2008, IARC Cancer Base No. 10, 1.2.

Frosst P, Blom HJ, Milos R, et al (1995). A candidate genetic risk factor for vascular disease: a common mutation in methelenetetrahydrofolate reductase. Nat Genet, 10, 111-3.

Fu LY, Dai LM, Li XG, Zhang K, Bai Y (2013). Association of methylenetetrahydrofolate reductase gene C677T polymorphism with polycystic ovary syndrome risk: a systematic review and meta-analysis update. Euro J Obstet Gynecol Repro Biol, 6, 8272-6.

Galvan-Portillo MV, Cantoral A, Onate-Ocana LF, et al (2009). Gastric cancer in relation to the intake of nutrients involved in one-carbon metabolism among MTHFR 677 TT carriers. Eur J Nutr, 48, 269-76

Giovannucci E, Rimm EB, Ascherio A, et al (1995). Alcohol, low-methionine-low-folate diets, and risk of colon cancer in men. J Natl Cancer Inst, 87, 265-73.

Giovannucci E (2001). An updated review of the epidemiological evidence that cigarette smoking increases risk of colorectal cancer. Cancer Epidemiol Biomarkers Prev, 10, 725-31.

Goyette P, Sumner JS, Milos R, et al (1994). Human methylenetetrahydrofolate reductase: isolation of cDNA, mapping and mutation identifi-cation. Nat Genet, 7, 195-200.

Haghighi MM, Radpour R, Mahmoudi T, et al (2009). Association between MTHFR polymorphism (C677T) with nonfamilial colorectal cancer. Oncol Res, 18, 57-63. 
Huang P, Zhou ZY, Ma HT, et al (2003). MTHFR polymorphisms and colorectal cancer susceptibility in Chongqing people. Acta Academiae Med Militaris Tertiae, 25, 1710-3.

Jang MJ, Kim JW, Jeon YJ, et al (2013). Polymorphisms of folate metabolism-related genes and survival of patients with colorectal cancer in the Korean population. GENE, 7, 39056.

Jemal A, Siegel R, Ward E, et al (2009). Cancer statistics, 2009. CA Cancer J Clin, 59, 225-49.

Jiang Q, Chen K, Ma X, et al (2005). Diets, polymorphisms of methylenetetrahydrofolate reductase, and the susceptibility of colon cancer and rectal cancer. Cancer Detect Prev, 29. 146-54.

Jin XX, Zhu ZZ, Wang AZ, Jia HR (2007). Association of methy $\neg$ lenetetrahydrofolate reductase $\mathrm{C677T}$ polymorphism with genetic susceptibility to colorectal cancer. World Chin J Digestol, 15, 2754-7.

Jin F, Qu LS, Shen XZ (2009). Association between the methylenetetrahydrofolate reductase C677T polymorphism and hepatocellular carcinoma risk: a meta-analysis. Diagn Pathol, 4, 39.

Kang BS, Ahn DH, Kim NK, Kim JW (2011). Relationship between metabolic syndrome and MTHFR polymorphism in colorectal cancer. J Korean Soc Coloproctol, 27, 7882.

Kennedy, DA, Stern SJ, Matok I, et al (2012). FolatesIntake, MTHFR Polymorphisms, and the Risk of colorectal cancer: a systematic review and meta- analysis. J Cancer Epidemiol, 2012, 952508 .

Kim YI (2003). Role of folate in colon cancer development and progression. J Nutrit, 133, 3731-9.

Kim DH,Ahn YO, Lee BH, Tsuji E, Kiyohara C, Kono S (2004). Methylenetetrahydrofolate reductase polymorphism, alcohol intake, and risks of colon and rectal cancers in Korea. Cancer Lett, 216, 199-205.

Kim JW, Park HM, Choi YK, et al (2011). olymorphisms in genes involved in folate metabolism and plasma DNA methylation in colorectal cancer patients. Oncol Rep, 25, 167-72.

Kim J, Cho YA, Kim DH, et al (2012). Dietary intake of folate and alcohol, MTHFR C677T polymorphism, and colorectal cancer risk in Korea. Am J Clin Nutr, 95, 405412.

Le Marchand L, Wilkens LR, Kolonel LN, Henderson BE (2005). The MTHFR C677T polymorphism and colorectal cancer: the multiethnic cohort study. Cancer Epidemiol Biomarkers Prev, 14, 1198-203.

Li H, Xu WL, Shen HL, et al (2011). Methylenetetrahydrofolate reductase genotypes and haplotypes associated with susceptibility to colorectal cancer in an eastern Chinese Han population. Genet Mol Res, 10, 3738-46.

Ma J, Stampfer MJ, Giovannucci E, et al (1997). Methylenetetrahydrofolate reductase polymorphism, dietary interactions, and risk of colorectal cancer. Cancer Res, 57, 1098-102.

Mantel N, Haenszel W (1956). Statistical aspects of the analysis of data from retrospective studies of disease. J Natl Cancer Inst, 22, 719-48.

Matsuo K, Hamajima N, Hirai T, et al (2002). Methionine synthase reductase gene $\mathrm{A} 66 \mathrm{G}$ poly morphism is associated with risk of colorectal cancer. Asian Pac J Cancer Prev, 3, 353-9.

Matsuo K, Ito H, Wakai K, et al (2005). One carbon metabolism related gene polymorphisms interact with alcohol drinking to influence the risk of colorectal cancer in Japan. Carcinogenesis, 26, 2164-71.

Mei Q, Zhou D, Gao J, et al (2012).The association between MTHFR $677 \mathrm{C}>\mathrm{T}$ polymorphism and cervical cancer: evidence from a meta-analysis. BMC Cancer, 12, 467-76.

Miao XP, Yang S, Tan W, Zhang XM, et al (2005). Association between genetic variations in methylenetetrahydrofolate reductase and risk of colorectal cancer in a Chinese population. Chin J Prev Med, 39, 409-11.

Mokarram P, Naghibalhossaini F, Saberi Firoozi M, et al (2008). Methylenetetrahydrofolate reductase C677T genotype affects promoter methylation of tumor specific genes in sporadic colorectal cancer through an interaction with folate/vitamin B12 status. World J Gastroenterol, 14, 3662-71.

Naghibalhossaini F, Mokarram P, Khalili I, et al (2010). MTHFR C677T and A1298C variant genotypes and the risk of microsatellite insta bility among Iranian colorectal cancer patients. Cancer Genet Cytogenet, 197, 142-51.

Niu YM, Shen M, Li H, et al (2012). No association between MTHFR A1298C gene polymorphism and head and neck cancer risk: a metaanalysis based on 9,952 subjects. Asian Pac J Cancer Prev, 13, 3943-7.

Otani T, Iwasaki M, Hanaoka T, et al (2005). Folate, vitamin B6, vitamin B12, and vitamin B2 intake, genetic polymorphisms of related enzymes, and risk of colorectal cancer in a hospital based case control study in Japan. Nutr Cancer, 53, 4250.

Ozen F, Metin Sen M, Ozturk Ozdemir O (2014). Methylenetetrahydrofolate reductase gene germ-line C677T and A1298C SNPs are associated with colorectal cancer risk in the turkish population. Asian Pac J Cancer Prev, 15, 7731-5.

Park KS, Mok JW, Kim JC (1999). The 677C > T mutation in 5,10 methylenetetrahydrofolate reductase and colorectal cancer risk. Genet Test, 3, 233236.

Parkin DM, Pisani P, Ferlay J (1999). Estimates of the worldwide incidence of 25 major cancers in 1990. Int J Cancer, $\mathbf{8 0}$, 827-41.

Prasad VV, Wilkhoo H (2011). Association of the functional poly morphism C677T in the methylenetetrahydrofolate reductase gene with colorectal, thyroid, breast, ovarian, and cervical cancers. Onkologie, 34, 422-6.

Promthet SS, Pientong C, Ekalaksananan T, et al (2010). Risk factors for colon cancer in Northeastern Thailand: interaction of MTHFR codon 677 and 1298 genotypes with environmental factors. J Epidemiol, 20, 329-38.

Qin YT, Zhang Y, Wu F, et al (2014). Association between MTHFR polymorphisms and acute myeloid leukemia risk: a meta-analysis. Plos one, $9,88823$.

Rai V, Yadav U, Kumar P, Yadav SK, Mishra OP(2014) Maternal methylenetetrahydrofolate reductase $\mathrm{C} 677 \mathrm{~T}$ polymorphism and down syndrome risk: a meta-analysis from 34 studies. Plos One, 9, 108552.

Rai V (2014a). Folate pathway gene MTHFR C677T polymorphism and risk of lung cancer in asian populations. Asian Pac J Cancer Prev, 15, 9259-64.

Rai V (2014 b). The methylenetetrahydrofolate reductase C677T polymorphism and breast cancer risk in Asian populations. Asian Pac J Cancer Prev, 15, 5853-60.

Russo A, Franceschi S, La Vecchia C, et al (1998). Body size and colorectal-cancer risk. Int J Cancer, 78, 161-5.

Ryan BM, Weir DG (2001). Relevance of folate metabolism in the pathogenesis of colorectal cancer. J Laboratory Clin Med, 138, 164-76.

Sachse C, Smith G, Wilkie MJ, et al (2002). Colorectal cancer study group: a pharmacogenetic study to investigate the role of dietary carcinogens in the etiology of colorectal cancer. Carcinogenesis, 23, 1839-49.

Sameer AS, Shah ZA, Nissar S, Mudassar S, Siddiqi MA (2011). Risk of colorectal cancer associated with the methylenetetra hydrofolate reductase (MTHFR) C677T polymorphism in the Kashmiri population. Genet Mol Res, 10, 1200-10.

Shannon B, Gnanasampanthan S, Beilby J, Iacopetta B (2002). A polymorphism in the methylenetetrahydrofolate reductase gene predisposes to colorectal cancers with microsatellite 
insta bility. Gut, 50, 520-4.

Slattery ML, Potter JD, Samowitz W, Schaffer D, Leppert M (1999). Methylenetetrahydrofolate reductase, diet, and risk of colon cancer. Cancer Epidemiol Biomarkers Prev, 8, 513-8.

Stang A (2010). Critical evaluation of the Newcastle-Ottawa scale for the assessment of the quality of nonrandomized studies in meta-analyses. Eur J Epidemiol, 25, 603-5.

Stroup DF, Berlin JA, Morton SC, et al (2000). Meta-analysis of observational studies in epidemiology: a proposal for reporting. meta-analysis of observational studies in epidemiology (MOOSE) group. JAMA, 283, 2008-12.

Tu YL, Wang SB, Tan XL (2012). MTHFR Gene polymorphisms are not involved in pancreatic cancer risk: A meta-analysis. Asian Pac J Cancer Prev, 13, 4627-30.

Wang J, Gajalakshmi V, Jiang J, et al (2006). Associations between 5,10-ethylenetetrahydrofolate reductase codon 677 and 1298 genetic polymorphisms and environmental factors with reference to susceptibility to colorectal cancer: A case-control study in an Indian population. Int J Cancer, 118, 991-7.

Weiwei Z, Liping C, Dequan L (2014). Association between dietary intake of folate, Vitamin B6, B12 \& MTHFR, MTR Genotype and breast cancer risk. PakJ Med Sci, 30, 106-10.

Wen YY, Yang SJ, Zhang JX, Chen XY (2013). Methylenetetrahydrofolate reductase genetic polymorphisms and esophageal squamous cell carcinoma susceptibility: a meta-analysis of case-control studies. Asian Pac J Cancer Prev, 14, 21-25.

Yan L, Zhao L, Long Y, et al (2012). Association of the maternal MTHFR C677T polymorphism with susceptibility to neural tube defects in offsprings: evidence from 25 case-control studies. Plos One, 7, 41689.

Yan Y, Hongjie Liang H, Ruolin Li R, et al (2013). XRCC3 Thr 241 Met polymorphism and ovarian cancer risk: a metaanalysis. Tumor Biol, 35, 2711-5.

Yang XX, Li FX, Yi J, et al (2010). An association of methylenetetrahydrofolate reductase reductase C677T and gastric cancer, colorectal cancer and lung cancer susceptibility. Guangdong Med J, 31, 2375-7.

Yin G,KonoS, ToyomuraK, etal(2004). Methylenetetrahydrofolate reductase C677T and A1298C polymorphisms and colorectal cancer: the fukuoka colorectal cancer study. Cancer Sci, 95, 908-13.

Yin G, Ming H, Zheng X, et al (2012). Methylenetetrahydrofolate reductase $\mathrm{C677T}$ gene polymorphism and colorectal cancer risk: A case control study. Oncol Lett, 4, 365-9.

You W, Li Z, Jing C, et al (2013). MTHFR C677T and A1298C polymorphisms were associated with bladder cancer risk and disease progression: a meta-analysis. DNA Cell Biol, 32, 260-7.

Yousef A, Shomaf M, Berger S, et al (2014). Allele and genotype frequencies of the polymorphic methylenetetrahydrofolate reductase and colorectal cancer among jordanian population. Asian Pac J Cancer Prev, 14, 4559-65.

Zeybek U, Yaylim I, Yilmaz H, et al (2007). Methylenetetrahydrofolate reductase C677T polymorphism in patients with gastric and colorectal cancer. Cell Biochem Funct, 25, 419-22.

Zhang YL, Yuan XY, Zhang Z, et al (2008). Relationship of genetic poly $\neg$ morphisms in methylenetetrahydrofolate reductase and alcohol drinking with the risk of colorectal cancer. Chin J Cancer Prev Treat, 15, 1298-301.

Zhang P, Gao X, Zhang Y, et al (2014). Association between MTHFR C677T polymorphism and venous thromboembolism risk in the chinese population: a meta-analysis of 24 casecontrolled studies. Angiol, 3319714546368.
Zhu F, Wang YM, QY Z (2010). A case control study of plasma homocysteine, serum folate, the polymorphism of methylenetet $\neg$ rahydrofolate reductase in colorectal cancer. J Southeast Univ Med Sci Edi, 29, 8892.

Zhu Q, Jin Z, Yuan Y, Lu Q, Ge D, Zong M (2011). Impact of MTHFR gene C677T polymorphism on Bcl 2 gene meth $\neg y l a t i o n$ and protein expression in colorectal cancer. Scand J Gastroenterol, 46, 436-45.

Zhuo X, Ling J, Zhou Y, et al (2012). Polymorphisms of MTHFR C677T and A1298C association with oral carcinoma risk: A Meta-Analysis. Cancer Investigat, 30, 447-52.

Zintzaras E (2006). Association of methylenetetrahydrofolate reductase (MTHFR) polymorphisms with genetic susceptibility to gastric cancer: a meta-analysis. J Hum Genet, 51, 618-24.

Zintzaras E, Lau J (2008). Synthesis of genetic association studies for pertinent gene-disease associations requires appropriate methodological and statistical approaches. $J$ Clin Epidemiol, 61, 634-45. 